\title{
O CONGRESSO MINEIRO E A EDUCAÇÃO PROFISSIONAL EM MINAS GERAIS: O ENSINO TÉCNICO PRIMÁRIO'
}

Irlen Antônio Gonçalves*

Carla Simone Chamon**

RESUMO: Este artigo analisa algumas iniciativas de implementação da Educação Profissional no âmbito das políticas públicas em Minas Gerais, entre fins do século XIX e início do XX. Nosso objetivo é compreender como foi pensada e construída a escolarização do trabalhador mineiro nesse momento e sua relação com o processo de produção do ideário educativo modernizador da república. A análise da documentação - Anais do Congresso Mineiro, Leis e Decretos -, produzida entre os anos de 1892 e 1911, deixa entrever o esforço empreendido pelas elites mineiras não apenas para qualificar o trabalhador, mas também para ensinar-lhe a ética do trabalho. Parte de um processo mais amplo, que buscava atender ao ideal de ordem e progresso a que as elites republicanas aspiravam, as políticas públicas de Educação Profissional tinham por fim a formação do trabalhador em Minas Gerais e sua inserção, como cidadão útil, na república recém-inaugurada.

Palavras-chave: Políticas Públicas. Ensino Técnico Primário. Educação Profissional. Formação Profissional.

\footnotetext{
* Doutor em Educação pela Universidade Federal de Minas Gerais (UFMG); Professor do Mestrado em Educação Tecnológica do Centro Federal de Educação Tecnológica de Minas Gerais (CEFET-MG) e Membro do Núcleo de Estudos de Memória, História e Espaço - NEMHE. E-mail: irlen@terra.com.br

* Doutora em Educação pela Universidade Federal de Minas Gerais (UFMG); Professora do Mestrado em Educação Tecnológica do Centro federal de Educação Tecnológica de Minas Gerais (CEFET-MG) e Membro do Núcleo de Estudos de Memória, História e Espaço - NEMHE. E-mail: carlachamon@terra.com.br
} 


\section{THE MINEIRO CONGRESS AND VOCATIONAL TRAINING IN MINAS GERAIS: THE ELEMENTARY TECHNICAL SCHOOL}

ABSTRACT: This article analyses some initiatives taken to implement education of the professional in the context of state policies in Minas Gerais at the end of the 19th, and in the beginning of the 20th, century. Our aim is to understand how the schooling of workers from Minas Gerais was conceptualized and built into the schooling system, at this time, and how this relates to a modernizing educational ideal for the Republic and its related production processes. The analysis of the document - Annals of the Congress of Minas Gerais, Laws and Decrees - produced between the years, 1892 and 1911, allows us to see the effort made by the elites of Minas Gerais, to, not only qualify the workers, but also to teach them a work ethic. As part of a larger process, that tried to answer to the ideal of "order and progress" aspired to by the republican elites, these state policies for vocational education intended to shape workers, as well as including them, as useful citizens, in the newly inaugurated republic.

Keywords: State Policies. Elementary Technical School. Training; Vocational Education. Professional Development.

Este artigo discute e analisa as políticas públicas de implementação da Educação Profissional, em Minas Gerais, em fins do século XIX e início do XX, a partir da leitura da legislação e das discussões travadas sobre o tema no âmbito do Congresso Mineiro. O que se quer aqui é compreender o processo de produção do ideário educativo modernizador, identificando aí o modo como a formação do trabalhador mineiro foi pensada e construída.

A implantação de políticas públicas para a formação profissional em Minas Gerais, no período republicano ${ }^{2}$, data de 1892 , quando a Lei de n. 41 instituiu o ensino profissional, no âmbito das escolas normais, do ensino agrícola e zootécnico, do curso comercial, de agrimensura e de farmácia. Posteriormente, em 1896, a Lei de n. 203 organizou o ensino profissional primário, prevendo a aprendizagem dos ofícios e seu funcionamento sob a orientação de um profissional com a competência do exercício da profissão. Essa modalidade de instrução, pensada para ser modelo de ensino, veio a ser implementada em diferentes locais do estado de Minas, com o objetivo de ser o centro de formação de operários e contramestres, tendo sido parâmetro de organização do ensino técnico, complementar ao primário, em 1911.

A análise da documentação - Anais do Congresso Mineiro, Leis e Decretos -, produzida entre os anos de 1892 e 1911, encaminha-se na 
direção da compreensão do processo de escolarização da classe trabalhadora. Por meio do resgate dos discursos oficiais, possibilitadores da leitura de como foram sendo construídas as políticas públicas nesse ramo da administração do Estado, a formação profissional aparece como um dos vetores de socialização das ideias republicanas.

Em 2 de julho de 1896, o então jovem deputado Mendes Pimentel encaminhou à mesa do Congresso Legislativo o projeto de organização do ensino profissional primário ${ }^{3}$. Com esse projeto, Mendes Pimentel propunha a criação, em Minas Gerais, dos Institutos de Educandos Artífices, cujo objetivo seria a formação de "operários e contramestres", por meio do ensino gratuito da destreza manual e dos conhecimentos técnicos às crianças das classes desfavorecidas, com idades entre 9 e 13 anos.

O ensino proposto, sob a forma de internato, contava com uma parte obrigatória e outra facultativa: eram obrigatórios o ensino de um ofício, o ensino primário, o desenho elementar, o desenho geométrico, a música, a ginástica e a instrução militar e, facultativa, a aprendizagem de mais de um ofício. O ensino elementar primário e o ensino de desenho seriam ministrados por professoras normalistas nomeadas pelo governo, e o ensino de ofício, por mestres contratados.

No ensino de desenho geométrico, o professor deveria incluir as três ordens clássicas de desenho, a saber: o desenho de máquinas, de ornatos de flores e animais e a composição e escultura de ornatos.

No ensino dos ofícios, de acordo com as demandas de cada local, os mestres ensinariam os ofícios de: armeiro, armador, abridor, alfaiate, chapeleiro, carpinteiro, cuteleiro, dourador, encadernador, entalhador, ferreiro, funileiro, fundidor, gravador, latoeiro, litógrafo, marceneiro, oleiro (arte cerâmica), ourives, pedreiro, sapateiro, sirgueiro, seleiro e correeiro, serralheiro, torneiro, tintureiro e tipógrafo.

Há, na proposição da criação dos Institutos de Educandos Artífices, desenvolvida por Mendes Pimentel e presente no seu discurso de encaminhamento do projeto, algumas questões sobre as práticas educativas e institucionais do ensino técnico que vinham se descortinando no cenário brasileiro e mundial. Entre elas destacamos: a íntima relação entre as propostas educativas e de instrução com as propostas de constituição de uma nação civilizada, a necessidade de educar e instruir o povo para a garantia da ordem social e a formação técnica, meio para incorporação do povo à nação. 
Essa é uma questão que perpassou o discurso de intelectuais, políticos e legisladores que estiveram imbuídos do pensar a educação republicana. Nesse momento, em que ocorria no país um forte desenvolvimento urbano e industrial, crescia entre os republicanos a preocupação em torno da necessidade de formação do trabalhador nacional, papel que deveria ser desempenhado pelas escolas. Essa formação deveria contemplar tanto as primeiras letras, condição de usufruto da cidadania, quanto o ensino técnico, condição de progresso material e de inserção do Brasil na modernidade, representada pela indústria e pelas relações livres de trabalho. Oferecendo ao operariado a inserção na sociedade moderna por meio do conhecimento das técnicas e das primeiras letras, o ensino profissional cumpriria seu objetivo no novo mundo do trabalho que surgia. $\mathrm{Na}$ afirmação de Carmem Vidigal Moraes, "diversas foram as instituições educacionais ou disciplinadoras organizadas pelas classes dominantes paulistas e dirigidas aos trabalhadores, aos filhos de trabalhadores, nacionais e imigrantes [...] 'aos sem trabalhos', 'aos vagabundos' e aos mendigos" (2003, p. 23).

A escola e a escola profissional seriam um instrumento de formação e disciplinamento das camadas pobres e trabalhadoras do Brasil, devendo contribuir tanto para unificar possíveis dissonâncias e fazer frente à desordem das ruas, transformando esses segmentos em participantes ordeiros do corpo social, quanto para a valorização do trabalho, marcado por séculos de escravidão e por uma consequente desvalorização (CUNHA, 2000a). Além disso, da formação e qualificação da força de trabalho esperava-se também o progresso econômico e a constituição de uma sociedade civilizada e moderna.

Em Minas, assim como em outras unidades da federação brasileira, não é raro encontrar no discurso das elites dirigentes, a ideia de que a educação era instrumento transformador da sociedade, como nos argumentos do senador Mello Franco ${ }^{4}$, quando do encaminhamento do projeto da primeira lei que propunha reformar a instrução pública em Minas Gerais:

Prevaleceu no espírito da comissão um pensamento geral, que a reorganização do país e o seu engrandecimento futuro dependem da iluminação do espírito das massas.

O pensamento dominante na Câmara e no seio da comissão tem sido abraçado geralmente no país e fora dele pelos homens mais eminentes. 
Costuma-se dizer que a instrução pública é o fator mais direto e mais poderoso na obra progressiva da civilização; mas convém atender-se que a instrução é um simples instrumento de que se pode fazer bom ou mau uso e não convém isolá-la no meio circundante em que o povo vive; mas dá-la de acordo com o estado atual do desenvolvimento social, porque não é possível assim, de chofre, alterar o estado de civilização (FRANCO, 1892, p. 1039).

Essa mesma linha de raciocínio marcou os argumentos de Mendes Pimentel na apresentação e na defesa de seu projeto de organização do ensino profissional primário, momento em que o deputado aponta como um dever dos mandatários do governo alicerçar, "na consciência nacional, a organização republicana por meio da verdadeira educação popular" (PIMENTEL, 1949, p. 30).

A educação popular à qual se referiu é a instrução pública responsável pela escolarização da massa, pela via da instrução primária e profissional. Nesse ímpeto, conclamava que os legisladores deveriam pensar na implementação do ensino profissional primário como forma de incorporação do proletário à nação, conforme salientou: "É preciso que nós, homens públicos e, portanto, previdentes, procuremos desde já incorporar o proletariado à nação, é imprescindível que desde já envidemos todo o esforço patriótico para educar o operário na escola do trabalho e do cumprimento dos deveres cívicos" (PIMENTEL, 1949, p. 33).

Reforçando o seu argumento, lançou mão da experiência francesa $^{5}$, quando afirmou que "levantar a oficina é levantar a Pátria". Segundo ele, em França, desenvolveu-se, de forma triunfal, a campanha em prol do ensino técnico primário. A partir de 1878, foram organizados vários estabelecimentos-modelo como forma de oferecer educação ao proletariado.

Realçar algumas questões do debate sobre o estabelecimento do ensino profissional primário, naquela realidade, é relevante para o nosso estudo, pois, conforme mencionado anteriormente, o autor da proposta de lei para o Estado mineiro era um leitor dos intelectuais franceses ${ }^{6}$, porque era com eles que dialogava.

Foi na década $1880^{7}$ que o governo francês iniciou a implementação de políticas públicas para a aproximação das aprendizagens manuais, ou seja, o ensino técnico das escolas primárias, com vistas à incorporação daquelas a estas, pela via do processo de escolarização da formação para o desempenho do ofício no comércio e na indústria. Aquelas aprendiza- 
gens criadas, segundo Buisson (1911), "pelas comunas ou pelos departamentos, para desenvolver, nos jovens que se destinavam aos trabalhos manuais, a destreza necessária e os conhecimentos técnicos", vinham se desenvolvendo no interior das oficinas das várias profissões. A Lei de 11 de dezembro de 1880 institui o ensino profissional primário público, como passo importante para efetuar as aproximações e a escolarização da formação das atividades manuais.

A pretensão dessas normativas de solucionar a dicotomização entre a oficina e a escola não ocorreu, mas descortinou calorosos debates sobre a questão (FERDINAND BUISSON, 1911; OUVRIER-BONNAZ, 2005; CHRISTIAN BIALÈS, 2005). O primeiro deles disse respeito às competências: houve, de fato, uma dupla autoridade sob a forma de "condominium", conforme expressou Buisson. Ao Ministério do Comércio e Indústria coube a competência sobre as Escolas Profissionais e ao Ministério da Instrução Pública às Escolas Primárias.

Assim, da forma como ficaram distribuídas as competências, acirrou-se uma divisão, considerada, por Ouvrier-Bonnaz, como ideológica. Segundo ele, "d'un côté, les écoles préparant à un métier (Commerce et Industrie); de l'autre, celles qui donnent une formation professionnelle (Instruction Publique et Beaux Arts)"” (2005, p. 5). Ademais, ampliaramse as oposições entre a oficina e a escola, o concreto e o abstrato, o geral e o particular, a teoria e a prática, o espírito e a mão.

Mas o debate que mais ganhou força foi o da pertinência ou não da necessidade de escolarização do ensino profissional. Bialès (2005) nos facilita a compreensão dos debates travados sobre a questão quando os sintetiza em dois grupos. O primeiro envolvia aqueles que eram favoráveis à escolarização e os que não o eram. Os favoráveis, entre os quais os ministros de Estado (da instrução e da indústria e comércio) e os industriais, embora por razões diferentes, lançaram mão dos argumentos de que tal modalidade de ensino, uma vez escolarizado, estaria a serviço da nação. Para os ministros, a compreensão do serviço à nação que as escolas manuais de aprendizagem prestariam relacionava-se ao papel que elas representariam na ação da política estatal republicana, com vistas ao prolongamento do tempo de permanência do aluno no ensino primário e, sobretudo, na promoção e na formação social da elite operária. Para os industriais, numa direção próxima aos representantes do governo, mas com o recorte demarcado pelo ponto de vista econômico, a formação 
deveria centrar-se, em maior proporção, na aprendizagem dos ofícios, e não na formação geral. Além disso, o espaço de organização da escola deveria ser adaptado ao máximo às demandas da especificidade da formação do operário.

$\mathrm{Na}$ outra ponta da linha, alguns parlamentares provenientes da classe operária opunham-se à escolarização, pois consideravam que a escola não tinha sido preparada para formar as atividades dos ofícios e, ainda, advogavam que tal aprendizagem teria melhor resultado se permanecesse no próprio âmbito da lida das profissões, onde estava presente o domínio do ofício (ou o segredo do ofício) e, bem assim, a preservação da identidade profissional.

No segundo grupo, Bialès destaca o debate entre Ferdinando Buisson, diretor da Instrução Pública de Paris (1879-1896), e Gustave Ollendorf, no qual o primeiro afirmou que a "meilleure école d'apprentissage, c'est une école primaire supérieur e oùl'apprentissage est comme encadré dans la culture générale". Por sua vez, Ollendorf replicara que o ensino profissional "doit être un enseignement spécial, ayant des ressources spéciales, et son autonomie absolue”"10 (2005, p. 7).

Atento aos acontecimentos que se desenrolavam nos países considerados civilizados, Mendes Pimentel não perdeu de vista a realidade mineira. Foi com os olhos postos na França e os pés em território mineiro que ele argumentou em favor da instituição de ensino profissional:

Sr. Presidente, não foram unicamente estes motivos de ordem teórica, antes outros de caráter prático que me levaram a apresentar o projeto que V. Exa. acaba de submeter à primeira discussão. Dia a dia estamos observando e tristemente constatando os resultados da falta de ensino técnico primário. $\mathrm{Na}$ cidade em que resido, em Barbacena, existem abundantes jazidas muito próprias para serem exploradas pela indústria cerâmica; entretanto as companhias ou associações que para tal fim ali se fundaram, não querendo se limitar ao fabrico de artefatos grosseiros, da telha e do tijolo, tiveram de, a custa de enormes sacrifícios, importar operários oleiros de Portugal, da Itália e da Alemanha (PIMENTEL, 1949, p. 36).

No mesmo compasso, dando ainda maior ênfase, relatou a experiência da construção da Capital mineira, em pleno processo naquele momento. 
E o que se está dando com a construção da Nova Capital mineira? O operário é estrangeiro, estrangeiro o contramestre, estrangeira toda a ferramenta empregada e quase todo o material, é importado; só não é estrangeira, só é nacional a alta direção técnica e o pessoal burocrático, porque nós, só nos temos ocupado com o ensino superior e com a formação do vasto proletário oficial dos empregados públicos (PIMENTEL, 1949, p. 36).

Nesses argumentos, destacamos duas das situações práticas mobilizadoras da atenção da plenária do Congresso. A primeira é a que traz para o debate o reconhecimento da existência, no Estado, de matéria-prima abundante, capaz de oferecer à sua realidade os recursos suficientes para não depender da importação cativa dos produtos manufaturados. Essa sua preocupação já havia sido destacada no início do seu discurso quando recordou que, em meio a alguns esforços de emancipação, como a da política, expressa na independência do Brasil e na abolição da escravatura, ainda faltava a da economia, pois seria essa que organizaria "a riqueza pública". Assim, para ele, a independência econômica tiraria o Estado brasileiro, e Minas por decorrência, do cativeiro das nações estrangeiras. Sobre a situação de cativo econômico, expressou:

Mas sob o ponto de vista econômico, é preciso dizê-lo bem alto, mesmo que pareça com isto ofender-se a susceptibilidade patriótica, nós somos uma espécie de feitoria das potências industriais, nós passamos a ser colônia de muitas metrópoles (PIMENTEL, 1949, p. 30,31).

Para ele, a batalha da busca emancipatória da economia estava na ampliação do setor industrial e na formação do trabalhador. Nesse sentido, afirmou que "o combate não se vai travando mais ao choque brutal de legiões armadas, mas fere-se dia por dia no afã das oficinas, na concorrência industrial" (PIMENTEL, 1949, p. 31).

A segunda questão prática levantada pelo deputado, bem relacionada à anterior, referiu-se à falta de mão de obra operária escolarizada e de ferramentas e materiais para o atendimento de determinadas atividades especializadas. Essas ausências, a do operário, da ferramenta e dos materiais, e essa última relacionada a materiais manufaturados, reforçavam a defesa da superação da autonomia econômica do Estado em relação aos países desenvolvidos, tendo a implantação e o desenvolvimento da indústria e a criação de escolas profissionais como forma de engrandecimento e progresso da nação. 
A defesa do progresso nacional, especificamente pela implantação da indústria e pela formação do operariado, fazia parte recorrente dos vários discursos dos republicanos em favor do que pode ser convencionado como busca da identidade da nação. Não foi sem sentido o tom pluralizado e enfático, dado por Mendes Pimentel, ao argumento em favor da aprovação do seu projeto de criação dos institutos profissionais. Dessa forma, ressaltou:

Nós que pregamos a República como o regime popular por excelência, nós que ou apostolamos a redenção política da nossa Pátria ou a ela prometemos e protestamos servir com fé e com lealdade, nós que em nossas bandeiras partidárias inscrevemos o velho lema, a velha divisa do governo do povo pelo povo, nós que só do povo tiramos toda a força que aqui nos congrega e que aqui nos mantém, nós, digamo-lo assim com franqueza e digamo-lo com verdade. [...] procuremos desde já incorporar o proletariado à nação [...] envidemos todo o esforço patriótico para educar o operário na escola do trabalho e do cumprimento dos deveres cívicos (PIMENTEL, 1949, p. 32-33).

É de fato um discurso de sonhos, polarizador de questões que evidenciavam um presente marcado por dada realidade que não mais atendia aos anseios de quem quer que nela se encontrasse inserido e um futuro revelador de um desejo que via e investia na possibilidade de, com uma chave mágica, abrir a porta da prosperidade, na direção do progresso, da emancipação econômica e política. Mas é, sobretudo, um sonho organizador de um pensamento, de um investimento, de tornar a república um sistema de governo viável. O projeto tramitou nas duas câmaras do legislativo", com certa tranquilidade, obtendo somente algumas poucas modificações e, num curto espaço de tempo ${ }^{12}$, foi aprovado.

Esse ímpeto organizador da República, que via na educação uma força modificadora da sociedade, tem a ver com o que pensavam os positivistas que estavam no exercício da vida pública e, por isso, buscavam, no rigor da lei, uma "proposta de incorporação do proletariado à sociedade moderna", por meio de "uma política social a ser implementada pelo Estado” (CARVALHO, 1998, p. 95).

Não foi sem razão o interesse de Mendes Pimentel pelo projeto de criação do ensino profissional primário. Como bem observou Silva e Faria Filho, para o deputado, 
em um regime republicano não devia haver espaço para ações que visassem exclusivamente os interesses de determinada fração social, [era] preciso levar sempre em consideração os efeitos das medidas tomadas pelo Estado em toda a sociedade. [...] Em sua opinião, a instrução pública, sobretudo no que tange à educação do proletário, constituía o problema capital do país, tendo o governo republicano até então "descurado da verdadeira educação popular" ao negligenciar o ensino profissional, único capaz de incorporar o povo à nação e provê-lo dos meios e habilitações necessários para lutar por uma vida digna. Lembrava então que um regime que havia sido teorizado como sendo do povo e pelo povo colocava-se sob ameaça ao menosprezar esse tipo de educação, já que esta era a única possibilidade de autonomia da nacionalidade. Deixando claro, portanto, o entrelaçamento que para ele havia entre o projeto político republicano e o campo educacional (SILVA; FARIA FILHO, 2007, p. 6-7).

Esse entrelaçamento do projeto republicano e educação tem relação direta com o que Berstein chama de vetores pelos quais passam a integração de múltiplas referências culturais, responsáveis pelo estabelecimento das normas e valores determinantes da representação que a sociedade irá fazer de si mesma e, no caso da república brasileira, no final do século XIX, o estabelecimento daquelas referências que, além de dar respostas às crises, angústias e problemas da sociedade, desempenharam o papel dominante, criando os espaços férteis para a geração de determinada cultura, no caso brasileiro, uma cultura republicana nascente. Não são respostas fortuitas e nem espaçadas no tempo, mas "respostas com fundamento bastante para que se inscrevam na duração e atravessem gerações". É uma resposta que somente com o tempo conseguirá se impor, penetrar "nos espíritos sob forma de um conjunto de representações de caráter normativo e acabe por surgir como evidente a um grupo importante de cidadãos" (BERSTEIN, 1998, p. 355-356).

A escola, a família, o meio de trabalho, as mídias, entre outros, são, para o autor, vetores de socialização política importantes. As escolas por transmitirem, "muitas vezes de maneira indireta, as referências admitidas pelo corpo social na sua maioria e que apoiam ou contradizem a contribuição da família” (BERSTEIN, 1998, p. 355).

A apresentação e a defesa do projeto de criação dos Institutos de Educandos e Artífices apresentado por Mendes Pimentel, sete anos após a proclamação da República, é uma das expressões vetoriais do regime nascente que tem, no seu ideal, "o culto do pequeno", por meio, primeiramente, do processo de escolarização das aprendizagens dos ofí- 
cios e, depois, ou ao mesmo tempo, da escolarização da criança. Essa não é somente uma posição isolada do mineiro Pimentel, pois está também presente nos discursos de outros intelectuais. A exemplo disso, vale lembrar o que foi dito pelo paulista Alberto Sales ${ }^{13}$ sobre a educação como força modificadora: "a educação é uma poderosa força modificadora que podemos aplicar livremente, mas cuja ação, lenta e demorada, só se torna apreciável depois de passadas muitas gerações". E ele não se limitou ao geral da educação, mas especificou o tipo: "O aparelho escolar, seu verdadeiro e único órgão, faz parte integrante da estrutura política geral, cujas modificações acompanha e deve, conseguintemente, ser considerado como uma das instituições mais importantes da nacionalidade" (SALES, 1901, p. 208). A afirmação de Sales indicia uma compreensão que ele tinha sobre a escola como vetor importante para fazer da república a república que se desejava. Essa escola a que se referiu é a escola pública, com um caráter eminentemente social, livre, gratuita, laica, científica e profissional.

Enfim, a proposição de Mendes Pimentel não logrou frutos práticos e perceptíveis no que se refere especificamente à implantação das escolas $^{14}$, mas fez parte de um tempo geracional, no qual ele não esteve sozinho, mas circundado por outros tantos pares, num projeto de fazer da república um governo.

Em 1906, dez anos após a proposição da implantação do ensino profissional primário e a criação dos Institutos de Educandos e Artífices - resguardando que o tema, o interesse, os esforços não ficaram abandonados, mas vivamente presentes no imaginário e, sobretudo, nos discursos dos intelectuais e políticos -, o ensino profissional foi incluído na reforma da instrução pública, passando a ser um componente a mais na nova organização do Ensino Primário, recebendo o tratamento de Ensino Técnico Prático e Profissional.

O Ensino Técnico Prático e Profissional foi instituído pela Lei de n. 444, de 3 de outubro de 1906, poucos dias após entrar em vigor a Lei de n. 439, de 28 de setembro de 1906, que propunha reformar o ensino primário e criar os grupos escolares. Essa relação de proximidade tem sua importância por ter sido o primeiro vinculado ao segundo pela Lei, uma vez que ele deveria ser ministrado no interior das escolas primárias, constituindo-se o Curso Técnico Primário. É importante ressaltar que a proposta de sua implantação recuperava a Lei de n. 203, de 1896, e sua 
respectiva regulamentação, o que resgata a proposição de Mendes Pimentel, alguns anos depois.

Duas observações se fazem necessárias. Uma relacionada ao retorno da proposição ocorrida em 1896, e outra, à vinculação entre ensino primário e ensino profissional. No caso da primeira, importa, ainda que rapidamente, salientar como a cultura política, especialmente a cultura política republicana brasileira, foi, ou vem, se constituindo historicamente. Não é nosso objetivo entender a noção de cultura política como algo engessado e circunscrito numa definição simplista. E, tampouco, criar uma nova noção. O que se pretende aqui é perceber, a partir da leitura do tempo histórico trabalhado, a forma, ou a maneira, como foram se sedimentando os discursos, principalmente dos políticos e intelectuais, ao ponto de se estabelecer como uma cultura, nesse caso, política, dentro de um investimento capaz de se fazer como governo. Nesse sentido, como faz Berstein (1998, p. 350), é necessário chamar a atenção para "a importância do papel das representações na definição de uma cultura política". Nesse caso, não há como negar a importância do discurso, no seu aspecto codificador e ritualístico/simbólico. À semelhança de Mendes Pimentel, os propositores da instituição do ensino técnico primário carregaram consigo uma visão e uma concepção do político, manifesta em discursos codificados, no vocabulário utilizado, nas palavras-chave, na repetição, e ritos e simbologias gestuais, visuais, capazes de produzir representações ao ponto de definir formas de identidade.

Assim, os discursos preliminares que ocorreram durante a tramitação da reforma da instrução ${ }^{15}$, dentro do Congresso Mineiro, mas também fora dele, espelharam a codificação das representações compartilhadas pelos republicanos, como vinha acontecendo desde o início de sua proclamação. Nesse sentido, as citações a seguir nos permitem perceber como a cultura republicana foi sendo tecida no compartilhar dos códigos, tomados como elementos constituintes de uma definição da identidade da escola, vetor importante para a construção da república que se desejava.

A preocupação com o progresso, vinculado à instrução, como forma de resgate ou de construção da vida social, vinha sendo recorrente nos discursos dos parlamentares, como o do já citado discurso do deputado Mendes Pimentel, e agora, conforme se segue, pelos Deputados Cônego Xavier Rolim e José Seixas ${ }^{16}$, membros da Comissão de Instrução 
Pública, por ocasião do encaminhamento do projeto substitutivo da reforma do ensino primário e normal. Eles viram na educação popular a possibilidade de progresso social, conforme afirmam:

A magna questão que, desde a segunda metade do século XIX, tem, não só preocupado, mas também agitado as nações que demandam o verdadeiro progresso social é a educação popular. Nesta obra ingente se empenham todos os povos que almejam o seu aperfeiçoamento e a felicidade pública, reconhecendo que a educação, pela sua influência decisiva na criança e na família elementos primitivos de toda sociedade - faz os costumes domésticos, inspira as virtudes sociais e prepara milagres inesperados de restauração intelectual, moral e religioso.

[...] Transformada a escola em instituto de educação intelectual, moral e física, formará homens fortes, distintos pelo caráter, nobres pelo espírito, generosos de coração, prontos para servirem a pátria nas funções sociais que tenham um dia de exercer (MINAS GERAIS, 1903, p. 341-342).

Vê-se que a ideia de progresso pela via da educação popular buscava um modelo de escolarização que pudesse atender à formação integral da criança, nos aspectos intelectual, moral e físico. Toda essa formação seria canalizada para o exercício das funções de serviço à pátria, com certeza republicana.

Na mesma direção, expressou o presidente Francisco Salles, em mensagem enviada ao Congresso Mineiro, em 1904, a que visava a formação profissional: à educação da criança para o exercício da cidadania. Como não existia e nem existe cidadania sem pátria, a sua referência tem, indiciariamente, a direção da formação da criança para a república. Eis o que afirmou:

A instituição dos grupos escolares, com uma sessão do ensino profissional, será muito proveitosa ao desenvolvimento da instrução pública no Estado. Ensino Profissional [...] visa o preparo da infância para o futuro cidadão (SALLES, 1904, p. 39-40).

Também o secretário de governo Delfim Moreira, no seu relatório ${ }^{17}$ ao presidente do Estado, em 1905, ao referir-se à instrução profissional, o fez vinculando-a à formação para a nação, como citado a seguir: 
uma grande causa preocupa seriamente a atenção dos que se interessam pelo progresso das artes e das indústrias em nosso país: é o estudo dos meios de proporcionar às classes menos abastadas a instrução suficiente e indispensável para se preparar o artista, o agricultor, o industrial, o mecânico e tantos outros operários de ofícios diversos, cujo desenvolvimento constitui a riqueza, a vida e a prosperidade da nação (MOREIRA, 1905, p. 128-129).

Igualmente, o discurso do deputado Xavier Rolim ${ }^{18}$, presidente da Comissão de Instrução da Câmara dos Deputados, na defesa do projeto de reforma da educação pública mineira, aparece recheado de códigos identitários, confluentes da partilha cultural, constituinte da república brasileira e, em particular, mineira. Disse Xavier Rolim:

Queremos que o Estado de Minas floresça? Queremos que o Brasil seja próspero e feliz? Queremos que a nossa Pátria brilhe com as fulgurações do Cruzeiro do Sul? Organizemos a escola, eduquemos a juventude.

Estabeleçam todos os Estados da grande Confederação Brasileira a educação popular, de modo que a mocidade aprenda, não só o exercer os direitos do cidadão, mas igualmente e principalmente cumprir os seus deveres públicos $\mathrm{e}$ particulares: assim teremos lançado os verdadeiros e sólidos alicerce da grandeza nacional; veremos reinar em nossa querida Pátria a paz, a ordem, a liberdade; e, em consequência, teremos segura a estabilidade das instituições republicanas, que com máximo carinho devemos sustentar.

[... Eduquemos o povo e rasgaremos para nossa querida Minas um futuro próspero e venturoso, porque, como muito garantiu o imortal Washington, a instrução popular é o fundamento mais sólido da felicidade pública e ensina o homem a não confundir a liberdade com a licença, amando a primeira e detestando a segunda (MINAS GERAIS, 1906, p. 337).

A segunda observação é a vinculação entre ensino primário e ensino profissional. Na Lei de 1896, não houve uma vinculação direta com o ensino primário regular, mas a proposta incluía tal formação em seu artigo $4^{\circ}$, parágrafo $2^{\circ}$, como ensino obrigatório. Com isso, podese afirmar que o ensino primário foi pensado em âmbito da formação profissional. De maneira diferente, a reforma de 1906 levou para dentro do ensino primário a formação profissional, conforme reza a Lei n. 444, de 1906, em seu art. $2^{\circ}$ : "O ensino técnico e prático será ministrado [...] alínea a: nas escolas primárias”. Assim, o argumento a favor esteve no conceber que o ensino primário somente ficaria completo com a anexação do ensino técnico, conforme a observação do deputado Xavier Rolim: 
A educação popular se divide em essencial e profissional. A primeira tem por fim formar o homem dando-lhe toda força da sua natureza e tornando-o capaz de preencher o seu nobre destino; a segunda prepara o homem social - o lavrador, o industrial, o arquiteto, o comerciante. São duas partes harmônicas que se completam. É do maior interesse de uma nação dar a seus filhos uma educação completa, porque disto, depende a sua marcha na estrada do progresso e da perfectibilidade (MINAS GERAIS, 1906, p. 329-330).

Vale ressaltar que, em ambas as propostas, vários modelos ${ }^{19}$ serviram de parâmetro ou, no mínimo, de inspiração. Quanto à aproximação entre o ensino primário regular e o ensino profissional, especificamente quanto à forma de organização, o modelo serviu como parâmetro, uma vez que ficou estabelecido na Lei de n. 444, de 3 de outubro de 1906, que a forma de organização teria como base a Lei de n. 203, de 18 de setembro de 1896, cujo autor tomou como base a reforma francesa. Ainda assim, no que se refere à funcionalidade, prevaleceu o ensino primário sobre o profissional, principalmente pelo caráter de anexo que ele teve nas experiências mineiras ${ }^{20}$.

Depois de alguns anos de experiência, a relação ensino primário e profissional teve desdobramento. Com o Decreto n. 3.191, de 9 de junho de 1911, o então Ensino Técnico Prático Profissional passou a ser configurado como Ensino Complementar, cujo fim era ampliar e integrar o primário, com "caráter acentuadamente profissional", conforme aludido nos arts. 340 e 343 do regulamento. Com a reforma, essa modalidade de ensino ganhou nova forma e ampliou, assim, seu âmbito de atuação na formação tanto da atividade na agricultura e no campo quanto na atividade industrial, nos grandes centros populosos. Quanto ao ensino que deveria oferecer, compreendia um arcabouço de estudos que ia desde a física e a química, passando pelo estudo de agronomia, trabalhos manuais, desenho, até a escrituração mercantil. Como se pode perceber, para atuar como professor nesse curso complementar, era preciso muito mais do que um conhecimento do fazer profissional: era preciso uma formação que incluísse conhecimentos mais gerais, que extrapolassem o conhecimento específico da técnica, como o domínio dos métodos de ensino, conforme prevê o art. 309: "No ensino de trabalhos manuais, poderão os professores seguir qualquer dos sistemas - froebeliano, Della-Voss ${ }^{21}$, sueco ou americano".

Como parte de um processo mais amplo, que buscava atender ao ideal de ordem e progresso a que as elites republicanas aspiravam, as polí- 
ticas públicas de escolarização, e aqui especificamente de escolarização de ofícios, visavam à formação do trabalhador em Minas Gerais e sua inserção, como cidadão útil, na república que se inaugurava. Aqui, a aposta na educação popular estava diretamente ligada à construção do progresso moral e material da sociedade.

No Brasil, e em Minas em particular, a formação do trabalhador foi acompanhada também pela questão da necessidade de reposição da mão de obra, decorrente da abolição da escravatura e do processo de adaptação e reestruturação da atividade do trabalho do imigrante estrangeiro. Importa ressalvar que o estado de Minas Gerais efetuou a transição do trabalho escravo para o livre com a incorporação do ex-escravo e do livre pobre, conhecido na literatura da época como trabalhador nacional. Nesse sentido, o esforço empreendido pelas políticas públicas mineiras não somente visou à qualificação do trabalhador nacional, mas também se organizou para ensiná-lo a ética do trabalho como forma de superação do "defeito mecânico", sedimentado ao longo dos quatro séculos de escravização, nos quais demarcou o tratamento do trabalho regular e braçal como a marca da desonra. 


\section{Referências}

BERSTEIN, Serge. A cultura política. In: RIOUX; SIRINELLI (Org.). Para uma história cultural. Lisboa: Estampa, 1998.

BIALES, Christian. Quelles nouvelles frontières pour l'enseignement technique? 2005. Disponível em : <http://www.christian-biales.net/pages/pedadida.html>. Acesso em: 21 ago. 2007. BUISSON, Ferdinand. Novean dictionaire de pedagogia et d'instruction primaire public.1911. Disponível em: <http://www.inrp.fr/edition-electronique/lodel/dictionnaire-ferdinand-buisson/document.php?id=2068\&format=print $>$. Acesso em: 15 ago. 2007.

CARVAlHO, José Murilo de. Pontos e bordados: escritos de história e política. Belo Horizonte: Editora UFMG, 1998.

CUNHA, Luiz Antônio. O ensino de oficios artesanais e manufatureiros no Brasil escravocrata. São Paulo: Unesp, Brasília, DF: Flacso, 2000a.

CUNHA, Luiz Antônio. O ensino de ofícios nos primórdios da industrialização. São Paulo: Unesp, Brasília, DF: Flacso, 2000b.

FRANCO, Virgílio M. Mello de. Anais do Senado 1891-1892. Belo Horizonte, Imprensa Oficial, 1892.

GAMA, Ruy. A tecnologia e o trabalho na história. São Paulo: Nobel, 1986.

IGLESIAS, Francisco. Política econômica do governo provincial mineiro (1835-1889). Rio de Janeiro: Instituto Nacional do Livro, 1958.

MAGALHÃES, Arnold. Relatório apresentado ao diretor do grupo escolar de Uberaba. Secretaria do Interior e Justiça. Arquivo Público Mineiro, Belo Horizonte, 1914.

MINAS GERAIS. Lei de n. 203, de 18 de setembro de 1896. Belo Horizonte, Imprensa Oficial.

MINAS GERAIS. Decreto de n. 1.127, de 14 de abril de 1898. Imprensa Oficial, Belo Horizonte.

MINAS GERAIS. Anais da Câmara dos Deputados. Belo Horizonte: Imprensa Oficial, 1903.

MINAS GERAIS. Anais da Camara dos Deputados. Belo Horizonte, Imprensa Oficial, 1906.

MINAS GERAIS. Lei de n. 439, de 28 de setembro de 1906. Belo Horizonte, Imprensa Oficial.

MINAS GERAIS. Lei de n. 444, de 3 de outubro de 1906. Belo Horizonte, Imprensa Oficial.

MINAS GERAIS. Decreto de n. 3.189, de 9 de junho de 1911. Belo Horizonte, Imprensa Oficial.

MORAES, Carmem Sylvia Vidigal. A socialização da força de trabalho: instrução popular e qualificação profissional no Estado de São Paulo. São Paulo: EDUSF, 2003.

MOREIRA, Delfim. Secretaria do Interior. Relatório apresentado ao Dr. Presidente do Estado de Minas pelo Secretário de Estado dos Negócios do Interior Dr. Delfim Moreira da Costa Ribeiro. Arquivo Público Mineiro, Belo Horizonte - Filme 071 G6, obra rara. 1905.

OUVRIER-BONNAZ. Evolutions conjuintes de la situation scolaire et de l'orientation em France: quelquer reperes pour une histoire des services d'orientation, 2005. INETOP Orientations. www.cnam.fr/instituts/inetop/. Acesso em 23 ago. 2007.

PIMENTEL, Francisco Mendes. Discurso pronunciado na sessão de 6 de julho de 1896 
na Câmara Mineira dos Deputados. In: MENDES PIMENTEL, Camilo \& outros. F. Mendes Pimentel: jornalista e político, professor, jurista. Rio de Janeiro: Oficinas Gráficas do Jornal do Brasil, 1949.

SALES, Alberto. O ensino público. O Estado de São Paulo, São Paulo, 5 dez. 1901, não paginado.

SALLES, Francisco Antônio. Mensagem ao Congresso Mineiro. Belo Horizonte, Imprensa Oficial, 1904.

SILVA, C. M. N.; FARIA FILHO, L. M. República e educação em Minas Gerais: ação/pensamento de Francisco Mendes Pimentel (1890-1910). IV Congresso de Pesquisa e Ensino de História da Educação em Minas Gerais, Juiz de Fora, 2007. 


\section{Notas}

1 Este artigo é produto de pesquisas desenvolvidas no âmbito dos projetos: A escolarização do trabalhador mineiro: as políticas públicas para a educação profissional (18891930), A escolarização das atividades manuais e a formação do trabalhador mineiro sob o ponto de vista do léxico republicano (1892-1920), coordenadas pelo professor Dr. Irlen Antônio Gonçalves, e História da escolarização do ensino de ofícios em Minas Gerais (1850-1950), coordenada pela professora Dra. Carla Simone Chamon. Esses projetos contam com o apoio financeiro da Fapemig e do CNPq e vêm sendo desenvolvidos no Núcleo de Estudos de Memória, História e Espaços - NEMHE, do Centro Federal de Educação Tecnológica de Minas Gerais.

2 Antes disso, as poucas iniciativas encontradas na província mineira, assim como no restante do país, eram pontuais, descontinuadas, além de, em sua maioria, estarem sob a responsabilidade de sociedades filantrópicas ou de igrejas. Sobre essa questão, confira Cunha (2000a) e Iglésias (1958).

3 Anais da Câmara dos Deputados (1896).

4 Anais do Senado mineiro da primeira legislatura (1892).

5 A experiência francesa a que Pimentel faz alusão são as reformas da instrução, promovidas por Jules Ferry, Ministro da Educação na França, na década de 1880. Entre as reformas propostas, destacam-se o estabelecimento da escola laica, gratuita e obrigatória; a exigência do título de professor para o exercício do magistério primário; e o estabelecimento do ensino técnico primário, pela lei de 11 de dezembro de 1880. Acrescentamos que Mendes Pimentel também levou para a sua discussão autores da Alemanha, da Inglaterra e do Chile.

6 Além de Ferry, foram citados outros intelectuais franceses, entre os quais: Charles Thomas Floquet (Primeiro Ministro - 1888-1889); Martin Nadaud (Parlamentar); Édouard Lockroy (Parlamentar e Ministro do Comércio e Indústria); Eugène Spuller (Parlamentar). Todos os citados tiveram participações significativas em prol do ensino técnico primário.

7 Durante a década de 1880, várias leis foram produzidas com o objetivo de desenvolver as aproximações entre o ensino primário e o profissional. A lei de outubro de 1886 foi a que mais representou o atendimento de tal empreendimento. Ela, assim, expressa no seu art. $1^{\circ}$ :

O ensino primário será dado:

$1^{\circ}$. nas escolas maternais e nas classes infantis;

$2^{\circ}$. nas escolas primárias elementares;

$3^{\circ}$. nas escolas primárias superiores e nas classes de ensino primário superior, anexas às escolas elementares e ditas "cursos complementares";

$4^{\circ}$. nas escolas manuais de aprendizagem, como definido na lei de 11 de dezembro de 1880.

8 De um lado, as escolas que preparam um ofício (Comércio e Indústria); de outro, as que dão uma formação profissional (Instrução Pública e Belas Artes). 
9 “a melhor escola de aprendizagem [de ofício] é uma escola primária superior, onde a aprendizagem está como parte da cultura geral".

10 “deve ser um ensino especial, tendo recursos especiais, e autonomia absoluta".

11 O poder legislativo mineiro se organizava por meio do sistema bicameral (Câmara e Senado).

12 Entrou na Câmara dos Deputados na $11^{\text {a }}$ sessão, aos 2 dias de julho de 1986, e foi aprovado na $66^{\mathrm{a}}$ sessão, aos 14 dias de setembro do mesmo ano. Foram, portanto, pouco mais de dois meses de tramitação.

13 Alberto Sales, notório propagandista republicano e pertencente aos quadros do Partido Republicano Paulista. Irmão do presidente da República Campos Sales. Conhecido como um dos ideólogos da República.

14 A Lei de n. 203, que propunha a organização do Ensino Profissional Primário, foi aprovada no Congresso Mineiro e sancionada pelo presidente do Estado Chrispim Jacques Bias Fortes, em 18 de setembro de 1896. Destaco, também, que ela foi regulamentada pelo Decreto de n. 1.127, de 11 de abril de 1898. Nesse mesmo ano, o presidente do Estado, Bias Fortes, determinou, pelo Decreto de n. 1.132, de 2 de maio de 1898, a instalação do primeiro Instituto de Ensino Profissional, na cidade de Barbacena. Vale a observação de que não foi encontrado nenhum documento dando notícias de que tal determinação tenha sido cumprida.

15 A tramitação da Reforma da Instrução ocorreu no período que vai de julho de 1903 a setembro de 1906, culminando com a Lei de n. 439, que autorizava o governo a reformar o ensino primário, normal e superior. Nessa Lei, contemplou-se o ensino profissional, estabelecendo o art. 14, parágrafo único, que “o Governo poderá ainda promover a educação profissional, quer dentro, quer fora do território nacional, de alunos pobres que revelarem decidida aptidão para as artes mecânicas ou para as belas artes".

16 Anais da Câmara dos Deputados mineiros (1903).

17 Relatório apresentado ao presidente do Estado de Minas pelo secretário de Estado dos Negócios do Interior, Dr. Delfim Moreira da Costa Ribeiro, no ano de 1905.

18 Anais da Câmara dos Deputados (1906).

19 Não foi somente o modelo que influenciou na formulação do texto da Reforma. Outros modelos serviram também de inspiração, como o modelo norte-americano e o inglês. Da Inglaterra, muito colaboraram as discussões de Herbert Spencer, sobretudo as publicadas no livro Da Educação Intelectual, Moral e Física.

20 Num levantamento feito entre os anos de 1906 e 1918, existiam 166 Grupos Escolares e, neles, somente foi possível encontrar o ensino profissional funcionando com regularidade em 8 .

21 O Russo Della Voss tornou-se conhecido após ter participado da Exposição de Filadélfia, nos Estados Unidos, em 1876, quando apresentou seu método de oficinas. O método consistia na associação das atividades da oficina com as aulas teóricas de física, química e matemática. O aluno, na oficina, tinha uma bancada e um jogo de ferramentas. Segundo Ruy Gama (1986, p. 146-147), “o trabalho era analisado, decomposto nas 
suas operações mais simples, e o aprendizado começava com o uso das ferramentas, indo até a montagem das peças fabricadas. Esses exercícios eram propostos na ordem crescente da dificuldade de execução, apoiados num desenho de trabalho e assistido por um mecânico perito".

Recebido: 06/12/2010

Aprovado: 05/03/2012

Contato:

Centro Federal de Educação Tecnológica de Minas Gerais (CEFET-MG)

Campus I

Av. Amazonas, 5253

Nova Suiça

CEP 30480-000

Belo Horizonte, MG

Brasil

Educação em Revista | Belo Horizonte | v.28 | n.02 | p.153-174 | jun. 2012 
